\title{
Methods of preparing internal combustion engine cylinder bore surfaces for frictional improvement
}

\author{
Kong Chung Hwa ${ }^{1,2}, D$.Ramasamy ${ }^{1,2,}{ }^{*}, K$. Kadirgama ${ }^{1,2}, M$. M.Noor ${ }^{1,2}, M$. M.Rahman ${ }^{1,2}, M$. \\ Samykano ${ }^{1,2}$ \\ ${ }^{1}$ Faculty of Mechanical Engineering, Universiti Malaysia Pahang, 26600 Pekan, Pahang, Malaysia \\ ${ }^{2}$ Automotive Engineering Centre, Universiti Malaysia Pahang, 26600 Pekan, Pahang, Malaysia
}

\begin{abstract}
Frictional losses piston to cylinder bore contact is a major sources of mechanical losses in an internal combustion engine (ICE). Traditional plateau honing produces a relatively rough cylinder bore surface with many valleys for oil retention and plateau surfaces that are usually has micro roughness's that causes mechanical friction to act as a bearing surface. A smooth polished dimpled surface is more ideal to achieve low friction and wear in an ICE. Alternative methods to create a smooth dimpled surface on a hypereutectic aluminum ADC12 substrate for frictional improvements are evaluated in this study using an oscillating wear tester (OWT). The methods include casting in the dimples in the aluminum matrix, sandblasting as well as embossing the pits. The texture samples are evaluated by examining the surface properties, measuring frictional coefficient as well as wear characteristics. It was found that the samples embossed with \#320 grit sandpaper and sandblasted with \#240 sieve sand samples had a reduced coefficient of friction $(\mu)$ of $23 \%$ at low sliding speeds before hydrodynamic lubrication mode and $6.9 \%$ in the fully hydrodynamic lubrication region.
\end{abstract}

\section{Introduction}

The wheel revolutionized human civilization as it enabled heavy transportation of goods and commodities, fostered trade, made construction of larger structures possible and revolutionized human transport in the form of wheel barrows, horse carriages and ox carts. It wasn't until the accidental discovery by an engineer by the name of Beauchamp Tower whom in his experiment observed that the sliding surfaces can be separated by a pressurized oil film that the idea of two sliding surfaces can be separated by a lubricant achieving minimal friction and wear. Reynolds furthered his findings and established the theories of hydrodynamic lubrication and in 1922, Sir William Bate Hardy coined the term boundary lubrication $[1,2]$.

Since the turn of the 20th century, burning hydrocarbon based fuels in Internal Combustion Engines (ICE) has become one of the primary energy generation methods.

\footnotetext{
* Corresponding author: deva@ump.edu.my
} 
Globally, the burning of fossil fuels provides $86.4 \%$ of energy demands [3]It saw applications far and wide from power generation to transport and even to operating a myriad of machines which together has powered mankind through the industrialization era and brought about the modern age as we know it today. The widespread application success of the ICE has hence contributed a major role in Carbon Dioxide (CO2) emissions to the atmosphere. According to the Intergovernmental Panel On Climate Change (IPCC), $57 \%$ of the total greenhouse emissions in 2007 came from the burning of fossil fuels alone which amounts to 32 billion metric tonnes of $\mathrm{CO} 2$ [4]. The average $\mathrm{CO} 2$ levels in the atmosphere has risen from $328 \mathrm{ppm}$ in 1970 to $399 \mathrm{ppm}$ in 2013[5]. As ICEs still are an integral to modern day living and its fuel source is not renewable, it is wise to invest some effort to make it cleaner and more fuel efficient to stretch oil reserve lifespans; allowing for more time for alternative renewable energy sources such as solar power to mature. An ICE that is cleaner and more efficient not only reduce running costs, but also helps reduce the its environmental footprint, preserving the environment for the future generations to come.

As governments worldwide begin to impose emission regulations to do their part to reduce greenhouse gasses in the atmosphere, there has been ever increasing importance for engine manufacturers to improve the emissions and

efficiency of their smaller engines as well. The first commitment period of the Kyoto Protocol (2008-2012) has just been passed where participating countries are required to reduce overall CO2 emissions from their 1990 levels over the next decade as stated in the agreement. The second commitment period (2013-2020) will see further $\mathrm{CO} 2$ cuts [6] which will push green engine designers to find extra efficiency from power plants and vehicles.

This in turn has pushed vehicle manufacturers to consider the use of aluminum as an engine block material to further reduce weight, saving fuel and reducing $\mathrm{CO} 2$ emissions in the process. Other improvements implemented include better fueling systems, improved engine head designs and changes aimed at reducing the mechanical friction of an ICE such as the use of smaller sized bearings as well as low friction cylinder bore surfaces.

Reducing the mechanical losses of an ICE is a key part in improving its efficiency. Besides the energy wasted heating up the engine as well as spent hot exhaust gasses, the second largest energy loss is from mechanical friction in the engine especially in the piston assembly [7-9]. In Figure 1, most of the power from combustion is converted in to heat. The remaining energy is turned in to work done and out of the work done by the ICE, a significant portion of it goes to overcoming mechanical and pumping losses [10, 11]. Figure 1 shows that the frictional losses from an ICE is mostly contributed by the piston assembly. Therefore, improvements in this area would yield the most effect to improving the overall fuel efficiency of an ICE. Aluminum especially in the form of its various silicate alloys is a lightweight metal that has good strength to weight ratios and has seen applications in many fields of engineering [12]. In the field of internal combustion engines, there has been an increasing trend where aluminium is used as the main material to produce engine blocks [13]. Aluminium is either cast around a cast iron liner or used as it is to from the cylinder block. The eutectic silicate alloy of aluminium, A390 has good strength to weight ratio and exhibits good wear properties due to its high silicate content preventing wear after the aluminium has been etched away exposing the silicate as the bearing surface.

This coupled with surface honing to create a crossed hatch pattern in the cylinder bore surface is the method currently deployed in making small ICEs for applications such as grass trimmers, chainsaws, small generators and other general purpose engines. To achieve minimal friction between the sliding surfaces in the engine bore, the ideal mating surfaces are polished and lubricated but this cannot be used as piston rings scrape off lubrication and the following reciprocations will result in unlubricated surfaces sliding past each other hence causing catastrophic wear and tear after short operation periods. [14, 15]. 


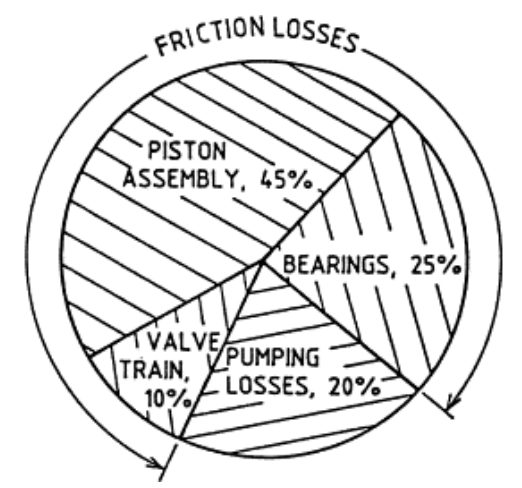

Fig. 1. The distribution of mechanical losses in a typical ICE [8].

Surface honing makes plateaued scratches on the surface of the cylinder but increases surface friction as it reduces surface conformity and creates more instances where the piston ring pack comes in to contact with the cylinder bore surface, which is known as boundary lubrication. Ideally, the cylinder bore has to be a surface that is polished to minimize inconformity between sliding surfaces which is the main cause of boundary lubrication mode [16]. Having said that however, an overly smooth conforming surface is detrimental when it comes to reciprocating wear systems as the reciprocating action wipes off the oil in one cycle and the following cycles would suffer from lubrication starvation and subsequently, catastrophic wear $[17,18]$. To achieve reduction in friction and wear, the sliding surfaces ideally need to have a smooth surface and a uniformly distributed array of recesses or dimples to allow oil retention but at the same time ensuring good surface conformity.

\section{Measurement of piston ring friction}

Piston ring tension of the compression rings used in this study is measured using a method developed by Tan and Ripin where the piston assembly is placed on a V-block and the tensile machine is set in compression mode. In this test, an Instron 3360 universal testing machine is used. The compression speed of the machine is set at $0.005 \mathrm{~mm} / \mathrm{s}$ and the compression is stopped when the diameter of the of the piston ring reaches the diameter of the cylinder bore. A V-block is used to locate the piston assembly during testing. The forces are resolved using a free body diagram as shown in Figure 2. The measurement is repeated three times and the average piston ring tension is calculated [19].The averaged result from the compression test shows that the piston ring tension of the compression ring is $17.9 \mathrm{~N}$. The elastic tension of the piston ring is given by Eq. (1).

$$
\Sigma F=F_{1}+F_{2}+F_{3}
$$

Since,

$$
F_{2}=F_{3}
$$

The surface area of contact between the piston ring and the cylinder bore is calculated via Eq. (2)

$$
\text { Area }=\pi \times r \times t
$$

where $r$ is the radius of the cylinder bore and $t$ is the thickness of the piston ring measured to be $1.5 \mathrm{~mm}$ giving an area of $169.6 \mathrm{~mm} 2$. Hence the nominal contact pressure of the 
piston ring to the cylinder bore for each given piston ring is calculated to be $254.7 \mathrm{kPa}$ using Eq. (3)

$$
\mathrm{P}=\frac{\text { Force }}{\text { Area }}
$$

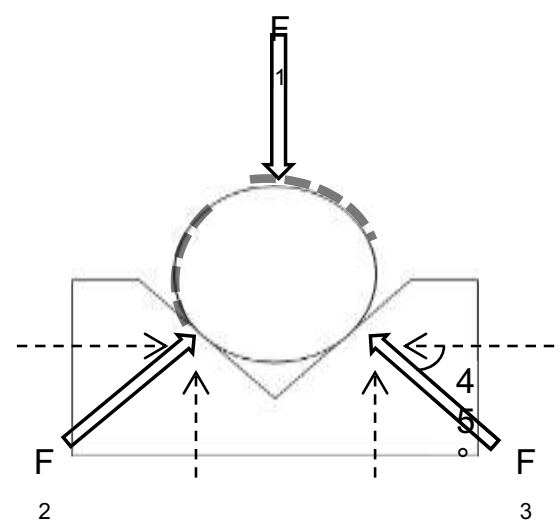

Fig. 2. Free body diagram of the piston assembly on the V-block during piston ring tension measurement. Dotted line indicate initial position of piston ring.

\section{Initial oscillating wear tester fabrication}

Initially an OWT design was conceptualized design criterions such as ease of sample fabrication to eliminate the need for complicated machining and enable higher repeatability in surface preparation and the ability to operate at a wide range of speeds that would be able to produce a broader representation of the friction curve behavior of an ICE as in Figure 3. To achieve these criterions that had been set, the OWT needed to have a small stroke that is similar to small ICEs and a low reciprocating weight to reduce the vibrations during testing. The next step was to make oil retention in the materials. The material was casted from aluminum and graphite was added to make peaks and valleys. The peaks and valleys undergo wear and due to their oil retention the friction coefficient is estimated to be reduced and a smoother engine operation is targeted.

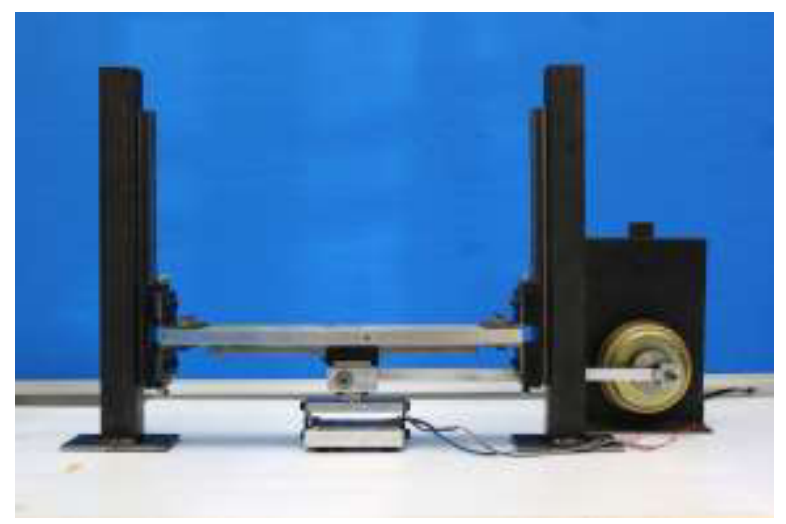

Fig. 3. Oscillating Wear Tester. 


\section{Results and discussion}

Oil retention volume, VO in $\mu \mathrm{m}^{3} / \mu \mathrm{m}^{2}$ is calculated via the Eq. (4) as described by [20] using the surface roughness values: Figure 4 shows the calculated oil retention volume for each of the samples in comparison with plateau honed surface. Conventional plateau honing would produce a surface with an oil retention volume of $0.83 \mu \mathrm{m} 3 / \mu \mathrm{m} 2$. Samples that were casted with graphite powder has even lower oil retention volume in comparison with the highest being only $0.61 \mu \mathrm{m}^{3} / \mu \mathrm{m}^{2}$ and lowest being $0.49 \mu \mathrm{m}^{3} / \mu \mathrm{m}^{2}$. The low oil retention volumes are attributed to the smoothness of the surface of the samples that were casted with graphite powder, having only small pits to retain oil after the piston rings sweep through the surface.

$$
\mathrm{V}_{\mathrm{O}}=\frac{(100-\mathrm{MR} 2)}{200} \cdot \mathrm{R}_{\mathrm{vk}}
$$

FigIn contrast to the low amounts of oil retention from the smooth surfaces of the samples casted with powdered graphite, surfaces that were sandblasted had much higher oil retention volumes which are attributed by their deep valleys that are formed when the impact of the sand particles on the surface of the substrate. Amongst the sandblasted samples, \#180 sieve sandblasted sample has the highest oil retention volume with 3.68 $\mu \mathrm{m}^{3} / \mu \mathrm{m}^{2}$ followed by \#240 sieve sandblasted sample with $2.41 \mu \mathrm{m}^{3} / \mu \mathrm{m}^{2}$. \#320 sieve sandblasted sample has an oil retention volume that is slightly higher than that of a conventional plateau honed surface with $1.18 \mu \mathrm{m}^{3} / \mu \mathrm{m}^{2}$.

Embossing also creates surfaces that have equally high oil retention volumes as sandblasted surfaces with \#320 grit sandpaper embossed surface having up to 4.46 $\mu \mathrm{m} 3 / \mu \mathrm{m} 2$ of oil retention due to the very deep valleys created from the embossing process because of the higher contact pressure between the surface asperities to the surface. The oil retention sharply falls off to a more modest $1.85 \mu \mathrm{m} 3 / \mu \mathrm{m} 2$ and $1.40 \mu \mathrm{m} 3 / \mu \mathrm{m} 2$ when $\# 480$ grit and \#640 grit sandpaper were used to emboss the surface as the valley depths of these two subsequent embossing are much less deep in comparison. Overall the sandblasted samples and embossed samples exhibited improved oil retention volumes over the conventional plateau honed sample which improves the oil film strength as well as their resistance to seizing during heavy operations. Their ability to maintain the oil retention even after excessive wear will also be good as the indentations created are deep enough to maintain the surface's ability to retain oil even after a significant amount of wear depth. Bearing area curve (BAC) or also known as the Abbott-Firestone curve or areal material ratio curve is cumulative probability density function of a surface profile's height. Typically a BAC is divided in to three sections; profile peaks, profile surface land and profile valleys. The cumulative material ratio of the peaks is the curve starting from the $100 \%$ point that falls rapidly in to a straight line which is the profile surface land. The surface profile land ends with a curve that steeply drops down to zero which represent the cumulative percentage of material height of the valleys on the surface profile. The beginning and the end of the bearing area land is denoted by the MR1 and MR2 points and the larger the bearing area land, generally the more tolerance it has for normal wear and tear. The BAC curve of the conventional plateau honed sample has a MR1 that starts at $9.8 \%$ and MR2 at $88.4 \%$. Samples casted with graphite powder however has a MR1 value that occurs at an earlier between $4.6 \%$ to $5.3 \%$ and their MR2 points occur even later between $93.8 \%$ to $96.4 \%$. This gives the graphite powder casted samples a slightly larger bearing area surface as seen in Figure 5 where the BAC of all three graphite powder casted samples are plotted along with the BAC of plateau honed surface for comparison. The bearing land area of the powder casted samples has a steeper gradient compared to plateau 
honed surface which indicates that the plateau honed surface flatter plateau region or peaks compared to the casted samples.

\section{Oil Retention Volume $\left(\mathbf{V}_{\mathrm{o}}\right)$}

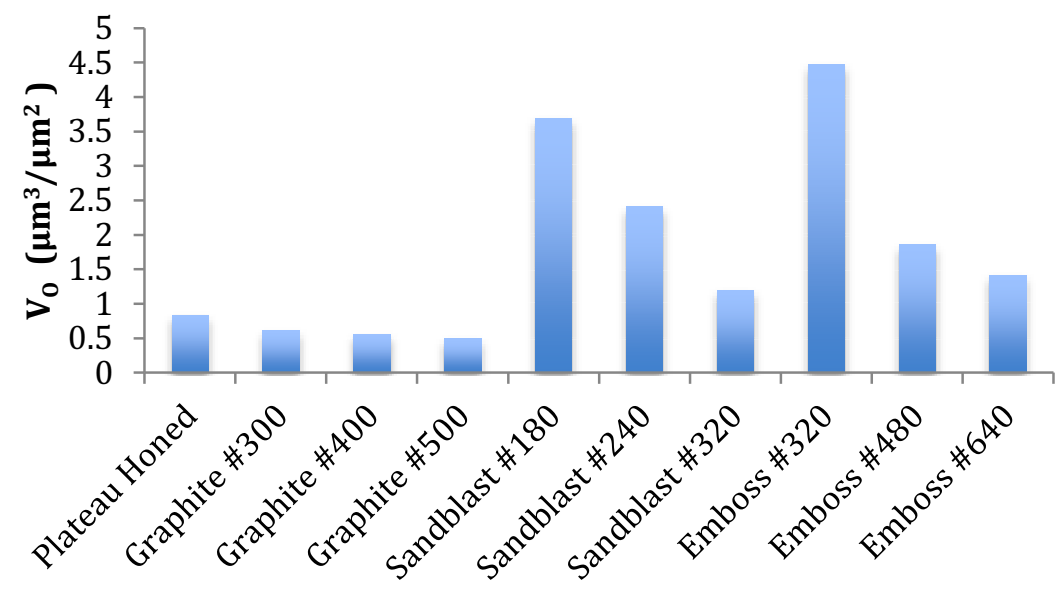

Fig. 4. Calculated oil retention volume of the samples.

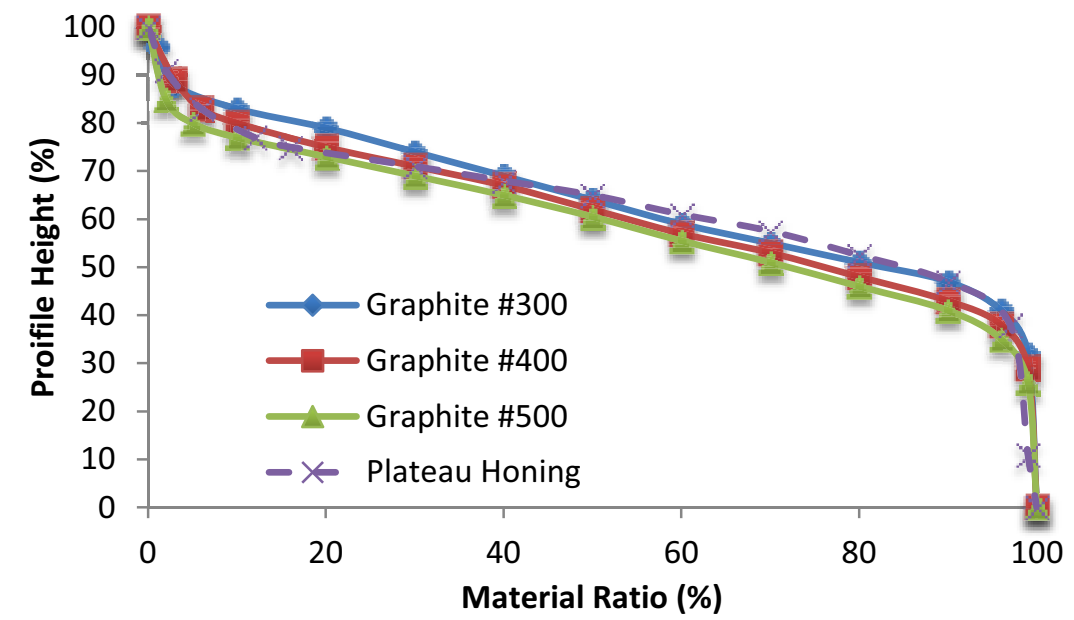

Fig. 5. Bearing area curve of Al-Si casted with sieved graphite powder in comparison to plateau honed bearing area curve.

The graphite addition seems to be beneficial in term peak and valley creation as in Figure 6 . When the BAC of plateau honed sample was compared to sandblasted samples, the trend that can be seen is that the bearing area straight lines are above the bearing area lines of the conventional plateau honed sample even though the MR1 figures occur later between $8.7 \%$ to $12.8 \%$. This is due to the nature of the surface roughness profiles that has valleys deeper than that of plateau honed surfaces. The deep valleys are shown at the end of the BAC of the sandblasted samples that fall off steeply from about $50 \%$ of the profile height as in Figure 7. The MR2 also occurs at about the same range as conventional plateau honed which is from $84.2 \%$ to $89.8 \%$ which would give it an advantage in oil retention volumes over conventional plateau honed surfaces. 
The surface embossed with \#320 grit sandpaper has BAC similar to that of a sandblasted sample with a low profile height $\%$ before MR 1 at $11.7 \%$ and MR2 occurs at $83.5 \%$ with more than $50 \%$ of the profile height in valleys. For the sample embossed with \#480 grit sandpaper, the BAC closely resembles that of a plateau honed surface with the MR1 and MR2 occurring slightly earlier at $8.5 \%$ and $84.4 \%$. When \#640 grit sandpaper was used, the resulting surface has a BAC that has higher peaks than a pleateau honed sample where the beginning part of the BAC is below the BAC of the plateau honed sample but the MR2 occurs at about the same range of profile height \%. Though the profile maybe a bit peaky but the bearing landing is flatterer than the other samples.

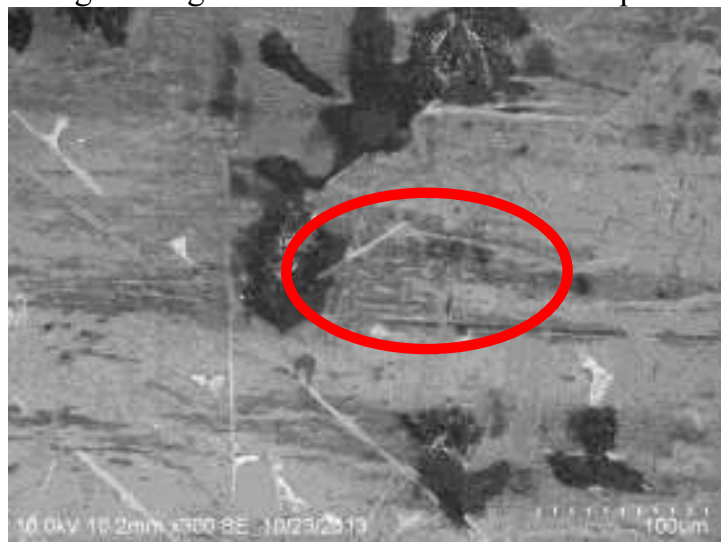

Fig. 6. Graphite 3 Carbon Deposits on the SEM.

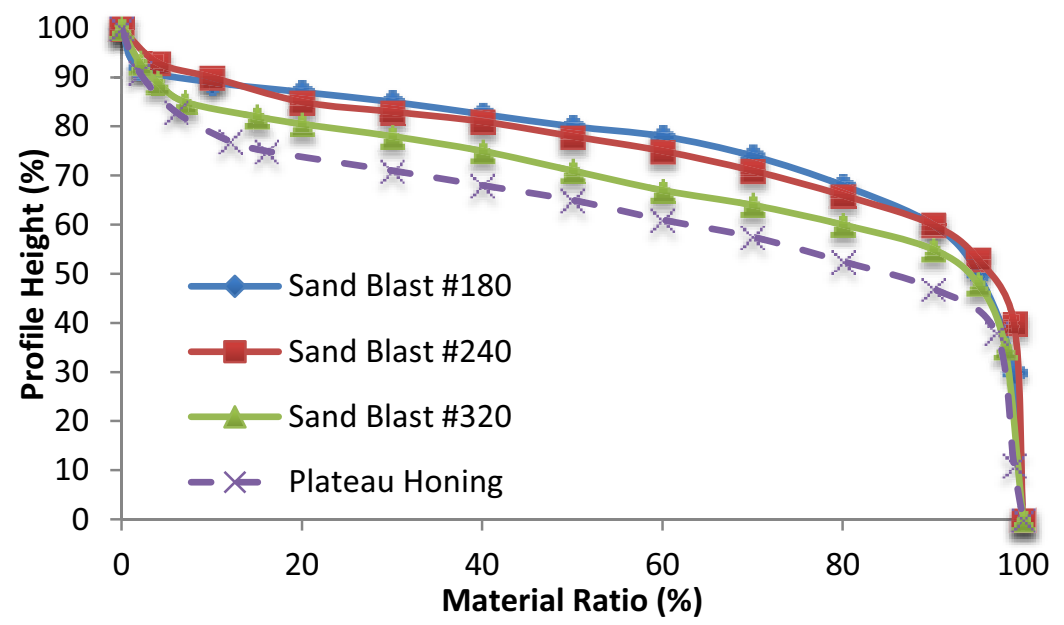

Fig. 7. Bearing area curve of Al-Si sandblasted with grated sand in comparison to plateau honed bearing area curve.

Peaks and valleys are created in sandblasted samples as in Figure 8 indicates that the samples are indeed creating oil retaining area which can aide the process of lubrication. For the embossed samples in comparison with plateau honed surface, there is a surprising amount of difference in the shape and the height of the BAC. Figure 9 is a plot of the BAC of the embossed samples in comparison to the plateau honed surface. 


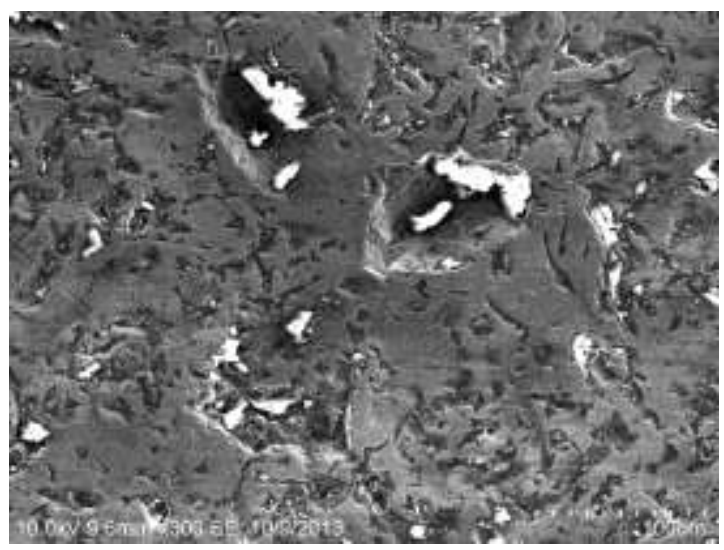

Fig. 8. Sand blast 3 porosity micro pits that increases oil retention.

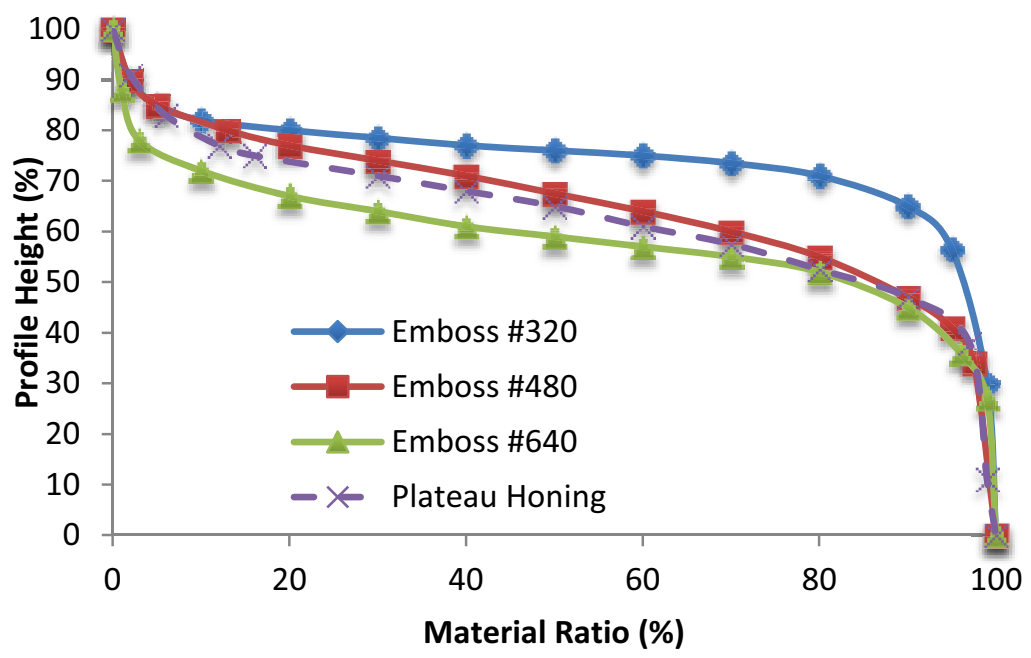

Fig. 9. Bearing area curve of Al-Si embossed with sandpaper in comparison to plateau honed bearing area curve.

Figure 10 shows that carbon deposit is similar to the EDX, with peak in Carbon value. The carbon addition shows good distribution of the valleys in Figure 11. The attrition of Aluminum in the sample increases as the wear is increased. The OWT running is make this possible. The Aluminum in the sample confirm that the material property is maintained. Based on Figure 11 the peaks and valleys occur as per BAC for the embosses sample. It is very similar to the plateau honed and can be described as a new method to increase the oil retention. 


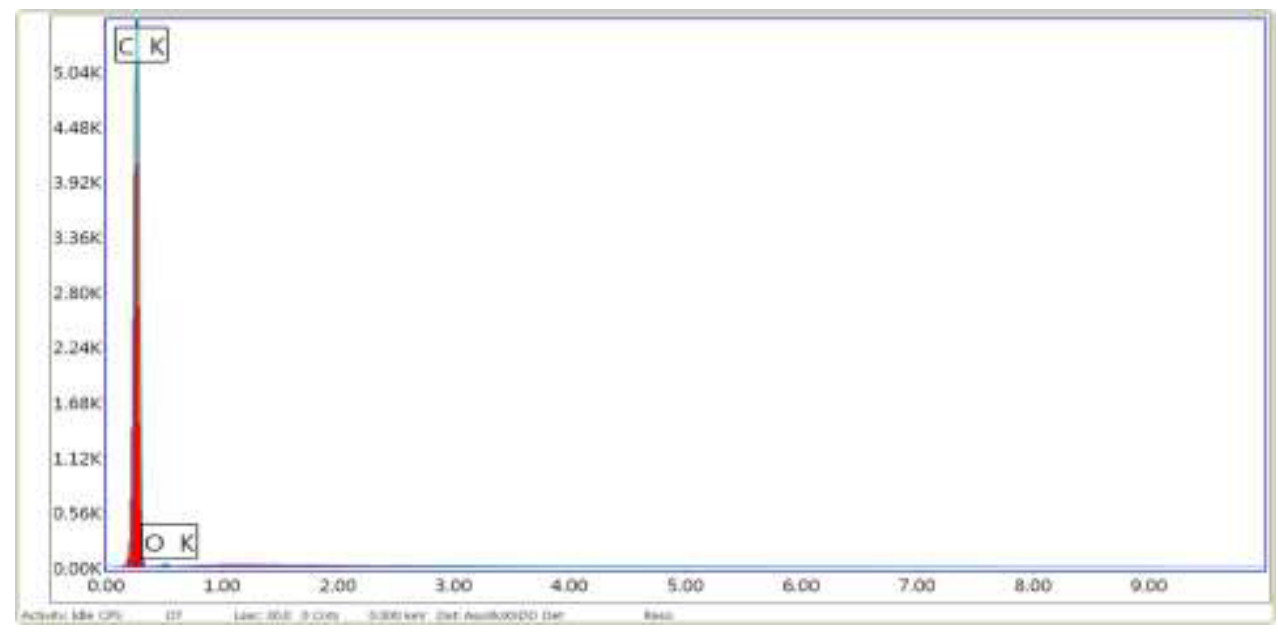

Fig. 10. EDX Showing the attrition of the sample.

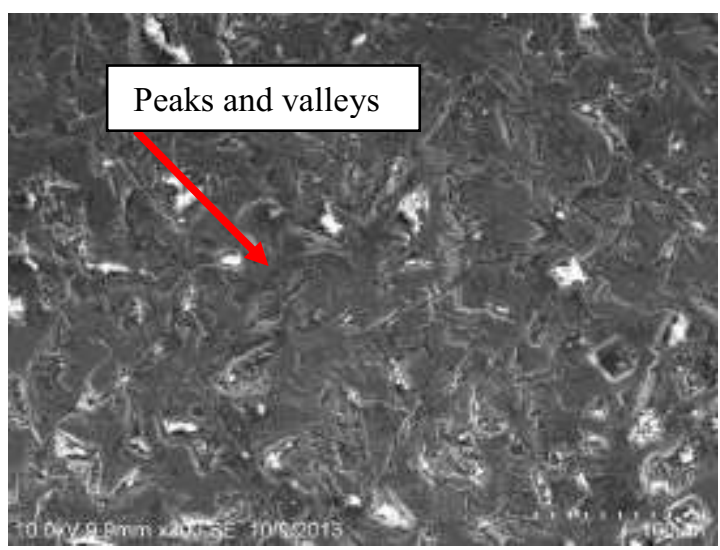

(a)

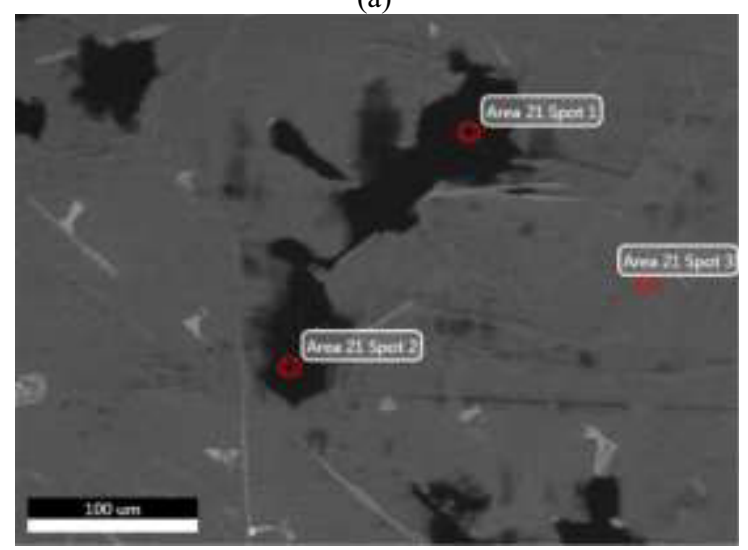

(b)

Fig. 11. Emboss 1 Surface is more distributed compared to plateau honing. 


\section{Conclusions}

From the surface measurements, frictional measurements and wear studies of hypereutectic aluminium-silicon (ADC12) alloy, the following conclusions can be made:

1. The samples that have undergone polishing to flatten out the peaks and has lower Ra than plateau honing have on average, $24 \%$ lower coefficient of friction than plateau honed surface which shows especially significantly at speeds of $300 \mathrm{rpm}$ and below and on average, $6 \%$ lower coefficient of friction at sliding speeds above $1200 \mathrm{rpm}$.

2. Hypereutectic aluminium-silicon alloy samples casted with graphite powder has significantly lower friction and wear rate attributed by the smooth polished surface that resembled a well-worn cylinder bore surface however suffer from low oil retention volumes which eventually led to lowered resistance to catastrophic wear.

3. Surfaces created from \#240 sieve sandblasting and \#320 grit embossing showed improvement over conventional plateau honed surface due to their lower mean surface roughness and similar skewedness values coupled with improved oil retention.

The authors would like to acknowledge Universiti Malaysia Pahang in the vote RDU 1403124 internal grants and Fakulti Kejuruteraan Mekanikal together with Automotive Engineering Research Group (AERG) for funding the research.

\section{References}

1. D. Dowson, A. Goldsmith, C. McNie, and S. Simith, A Tribological Study of Metal-onmetal Total Replacement Hip Joints: London, Professional Engineering Publishing, 2003.

2. G. Stachowiak and A. W. Batchelor, Experimental methods in tribology vol. 44: Elsevier, 2004.

3. A. E. Outlook, "Energy information administration," Department of Energy, 2010.

4. I. P. O. C. Change, "IPCC," Aspectos Regionais e Setoriais da Contribuição do Grupo de Trabalho II ao $4^{\circ}$ Relatório de Avaliação "Mudança Climática 2007" do IPCC, 2007.

5. S. M. Miller, S. C. Wofsy, A. M. Michalak, E. A. Kort, A. E. Andrews, S. C. Biraud, et al., "Anthropogenic emissions of methane in the United States," Proceedings of the National Academy of Sciences, vol. 110, pp. 20018-20022, 2013.

6. U. Nations, "Kyoto protocol to the united nations framework convention on climate change," 1998.

7. J. B. Heywood, Internal combustion engine fundamentals vol. 930: Mcgraw-hill New York, 1988.

8. C. Taylor, "Automobile engine tribology - design considerations for efficiency and durability," Wear, vol. 221, pp. 1-8, 1998.

9. D. Ramasamy, Z. Zainal, K. Kadirgama, and H. W.-G. Briggs, "Effect of dissimilar valve lift on a bi-fuel CNG engine operation," Energy, vol. 112, pp. 509-519, 2016.

10. P. Mishra, S. Balakrishnan, and H. Rahnejat, "Tribology of compression ring-tocylinder contact at reversal," Proceedings of the Institution of Mechanical Engineers, Part J: Journal of Engineering Tribology, vol. 222, pp. 815-826, 2008.

11. A. Spencer, A. Almqvist, and R. Larsson, "A numerical model to investigate the effect of honing angle on the hydrodynamic lubrication between a combustion engine piston ring and cylinder liner," Proceedings of the Institution of Mechanical Engineers, Part J: Journal of Engineering Tribology, vol. 225, pp. 683-689, 2011.

12. J. G. Kaufman, Introduction to aluminum alloys and tempers: ASM International, 2000 . 
13. J.-m. Chen and J.-h. Jia, "Investigation of the tribological behavior of an aluminum alloy with embedded materials," Materials Science and Engineering: A, vol. 302, pp. 222-226, 2001.

14. Z. Dimkovski, N. Allard, C. Anderberg, F. Strömstedt, S. Johansson, B.-G. Rosen, et al., "Cylinder Liner Honed Surface Optimisation-a Manufacture-CharacterisationFunction Study," in 1st Swedish Production Symposium, 28-30 August, Gothenburg, Sweden, 2007, p. 9.

15. E. Tomanik, "Friction and wear bench tests of different engine liner surface finishes," Tribology International, vol. 41, pp. 1032-1038, 2008.

16. L. Mourier, D. Mazuyer, F. Ninove, and A. Lubrecht, "Lubrication mechanisms with laser-surface-textured surfaces in elastohydrodynamic regime," Proceedings of the Institution of Mechanical Engineers, Part J: Journal of Engineering Tribology, vol. 224, pp. 697-711, 2010.

17. M. Organisciak, G. Cavallaro, and A. Lubrecht, "Variable lubricant supply of a starved hydrodynamic linear contact: lubricant lateral flow for smooth and laser textured surfaces," Proceedings of the Institution of Mechanical Engineers, Part J: Journal of Engineering Tribology, vol. 221, pp. 247-258, 2007.

18. D. Ramasamy, Z. Zainal, R. Bakar, and K. Kadirgama, "Mass fraction burn comparison of compressed natural gas and gasoline," in Applied Mechanics and Materials, 2014, pp. 442-446.

19. Y.-C. Tan and Z. M. Ripin, "Frictional behavior of piston rings of small utility twostroke engine under secondary motion of piston," Tribology International, vol. 44, pp. 592-602, 2011.

20. M. Priest and C. Taylor, "Automobile engine tribology—approaching the surface," Wear, vol. 241, pp. 193-203, 2000. 